\title{
In vitro Anti-viral Activity of Psoraleae Semen Water Extract against Influenza A Viruses
}

\author{
Jang-gi Choi, Young-Hee Jin, Ji-Hye Kim, Tae Woo Oh, Nam-Hui Yim, Won-Kyung Cho* \\ and Jin Yeul Ma*
}

Korean Medicine (KM) Application Center, Korea Institute of Oriental Medicine (KIOM), Daegu, South Korea

\section{OPEN ACCESS}

Edited by:

Bey Hing Goh,

Monash University Malaysia Campus,

Malaysia

Reviewed by:

Jia-bo Wang,

302 Military Hospital of China, China

Fang-Rong Chang,

Kaohsiung Medical University, Taiwan

${ }^{*}$ Correspondence:

Won-Kyung Cho

wkcho@kiom.re.kr

Jin Yeul Ma

jyma@kiom.re.kr.

Specialty section:

This article was submitted to

Ethnopharmacology,

a section of the journal

Frontiers in Pharmacology

Received: 19 August 2016 Accepted: 14 November 2016 Published: 30 November 2016

Citation:

Choi JG, Jin YH, Kim JH, Oh TW, Yim NH, Cho WK and Ma JY (2016) In vitro Anti-viral Activity of Psoraleae Semen Water Extract against Influenza A Viruses.

Front. Pharmacol. 7:460. doi: 10.3389/fphar.2016.00460
Influenza causes respiratory infections and poses health risks to humans and animals; its effects are complicated by increasing resistance to existing anti-influenza viral agents. Therefore, novel therapeutic approaches against influenza virus infection are required. Psoraleae semen has been widely used in traditional medicine in Korea, Taiwan, China, and Japan for treating and preventing various diseases. In this study, we examined the anti-viral activities and mechanism of action of the water extract of Psoraleae semen (WPS) using RAW 264.7 and MDCK cells. We found that pre- and post-treatment with $100 \mu \mathrm{g} / \mathrm{mL}$ WPS markedly inhibited influenza A virus replication as assessed using a green fluorescent protein reporter virus, reduced viral protein expression (NS-1, PA, HA, PB-1, M1, and M2), and inhibited NA and HA activities. Mechanism studies revealed that WPS induced type I interferon cytokine secretion and subsequent stimulation of an antiviral state in RAW 264.7 cells. Further, WPS exerted inhibitory effects on neuraminidase in influenza virus strains $\mathrm{H} 1 \mathrm{~N} 1$ and H3N2. Meanwhile, WPS exhibited inhibitory effects on hemagglutination in $\mathrm{H} 3 \mathrm{~N} 2$ but not in $\mathrm{H} 1 \mathrm{~N} 1$. Based on these results, WPS serves as an immunomodulator and inhibitor of influenza hemagglutinin and neuraminidase. Our results suggest that WPS is a promising source of novel anti-influenza drug candidates.

Keywords: Psoraleae semen water extract, influenza A virus, anti-viral activity, H1N1, H3N2

\section{INTRODUCTION}

Influenza viruses belong to the Orthomyxoviridae family. There are three types of influenza viruses: A, B, and C (Zambon, 1999). Influenza virus A can infect humans and different animals, including domestic and wild birds (Capua and Alexander, 2004). However, infection by type $B$ and C viruses is mainly restricted to humans (Capua and Alexander, 2004). Influenza A virus (IAV) is the most serious influenza type as IAV infection can result in serious respiratory illness, respiratory complications, major economic loss, and death; additionally, the virus is particularly virulent among the elderly (Monto and Sullivan, 1993; Fleming et al., 2000; Fiore et al., 2009). Vaccines represent the most effective strategy for controlling influenza virus infection, but influenza vaccines have disadvantages, including inadequate protection, high cost, difficulty in predicting representative strains, and time requirements for design and production (Hayden, 2006; Fiore et al., 2009). Therefore, alternative strategies are required for efficiently controlling influenza outbreaks. There are two classes of anti-influenza drugs: neuraminidase (NA) inhibitors (oseltamivir, zanamivir, and peramivir) and adamantanes (amantadine and rimantadine; Meijer et al., 2014). However, high resistance levels have been reported for adamantanes against IAV, and 
these drugs are ineffective against influenza B virus (Centers for Disease and Prevention, 2006; Ison, 2011). NA inhibitors are widely used for treating and preventing influenza virus infection (Meijer et al., 2014). Numerous reports have illustrated that IAVs develop resistance to oseltamivir, zanamivir and peramivir (Centers for Disease and Prevention, 2006; Bouvier et al., 2008; Hurt et al., 2009). Further, NA inhibitors have several side effects (Kaji et al., 2005). Thus, there is a critical need to develop novel anti-influenza drugs to control and prevent future influenza pandemics and epidemics.

The innate immune system that includes type I interferons (IFNs) promotes innate anti-viral and anti-bacterial immunities (Anderson, 2000). Type I IFNs, namely $\alpha$ and $\beta$, are regulated by IFN regulatory factor (IRF)-7, IRF-3, NF- $\kappa$, and several intracellular signaling molecules, which are activated by germline-encoded pattern recognition receptors recognizing the molecular pattern specific to microorganisms (Marié et al., 1998; Sato et al., 2000). During viral infection, rapid IFN production is needed to prevent the spread of the virus in the host. Medicinal plants have been the most important sources of medicine worldwide for some time, and they will be continue to serve as sources of novel remedies for humans. Medicinal plants exhibit numerous beneficial therapeutic properties, and it is thought that the mechanisms involved in these effects are due to the modulation of innate immunity. In particular, a lot of extracts or substances from medicinal herbs or plants have anti-viral effects against infectious viruses (Cowan, 1999; Cho et al., 2015). Therefore, natural product or standardized plant extracts provide unlimited opportunities for new anti-viral drugs with high efficacies, low toxicities, and minor side effects.

Psoraleae semen (PS) has been widely used in traditional Korean, Chinese, and Asian herbal medicine to treat various diseases and conditions such as several skin diseases including leukoderma, cardiovascular diseases, nephritis, osteoporosis, cancer, and hair loss (Khushboo et al., 2010; Zhang et al., 2016). Additionally, PS extracts and active components possess many pharmacological and biological activities, including, estrogenic, anti-microbial, anti-depressant, anti-inflammatory, anti-oxidant, hypotensive, osteoblastic, hepatoprotective, and anti-tumor activities (Zhang et al., 2016). The main PS components include flavonoids, coumarins, and meroterpenes, and the major active compounds are bakuchiol, bavachin, angelicin, psoralen, and corylifolin (Zhang et al., 2016). Psoralen inactivates influenza viruses, herpes simplex viruses, and vesicular stomatitis virion RNA polymerase activity (Nakashima et al., 1979; Redfield et al., 1981), and angelicin derivatives inhibit influenza virus (Yeh et al., 2010). Recently, bakuchiol was shown to have anti-influenza viral activity by Nrf2 activation (Shoji et al., 2015). Consequently, a PS extract could be a candidate with anti-influenza virus activity. We hypothesize that water extract of PS (WPS) induces an anti-viral state in murine macrophage cells (RAW 264.7) via the modulation of the immune response, induction of anti-viral cytokines, and overall inhibition of virus replication.

Here we investigated WPS-induced signaling molecules and confirmed the immunomodulatory potential of these molecules to regulate the innate immune response of PS, which may be responsible for its anti-viral activity in murine macrophage cells. Further, we evaluated PS efficacy against IAVs in vitro. Finally, prophylactic WPS efficacies against divergent influenza A subtypes, including $\mathrm{H} 1 \mathrm{~N} 1$ and $\mathrm{H} 3 \mathrm{~N} 2$, were assessed.

\section{MATERIALS AND METHODS}

\section{WPS Preparation}

The PS identity obtained from Yeongcheon Oriental Herbal Market (Yeongcheon, Korea) was first certificated by Professor Ki Hwan Bae (College of Pharmacy, Chungnam National University, Daejeon, Korea), and PS was stored in the KMApplication Center herbarium, Korea Institute of Oriental Medicine. To prepare WPS, dried PS $(50 \mathrm{~g})$ was soaked in distilled water $(1 \mathrm{~L})$ and then heat-extracted at $115^{\circ} \mathrm{C}$ for $3 \mathrm{~h}$ in a Cosmos-600 Extractor (Gyeonseo Co., Incheon, Korea). After filtration through standard testing sieves $(150 \mu \mathrm{m}$, Retsch, Haan, Germany), WPS was freeze-dried and stored in desiccators at $4^{\circ} \mathrm{C}$. The amount of WPS powder collected was $15.6 \mathrm{~g}$, and the yield was $12.96 \%$.

\section{Cells and Viruses}

RAW 264.7 and MDCK cells were obtained from the American Type Culture Collection (Manassas, VA, USA). Cells were maintained in DMEM or RPMI 1640 (Lonza, Walkersville, MD, USA) supplemented with $10 \%(\mathrm{v} / \mathrm{v})$ heat-inactivated fetal bovine serum (Cellgro, Manassas, VA, USA) and penicillin $(100 \mathrm{U} / \mathrm{mL}) /$ streptomycin $(100 \mu \mathrm{g} / \mathrm{mL})$ at $37^{\circ} \mathrm{C}$ with $5 \% \mathrm{CO}_{2}$. Influenza $\mathrm{A} / \mathrm{PR} / 8 / 34(\mathrm{H} 1 \mathrm{~N} 1)$ and green fluorescent protein (GFP)-tagged H1N1 (H1N1-GFP) were donated by Dr. JongSoo Lee, College of Veterinary Medicine, Chungnam National University. Influenza A strains H3N2 (KBPV-VR-32) and H1N1 (KBPV-VR-33) were obtained from Korea Bank for Pathogenic Viruses. H1N1, H3N2, and H1N1-GFP were propagated in the allantoic fluid of 10-day-old chicken embryos.

\section{Reagents and Antibodies}

Recombinant mouse IFN- $\beta$, ribavirin, zanamivir, and lipopolysaccharides from Escherichia coli were obtained from Sigma Chemical Co. (St. Louis, MO, USA). Anti-IRF3, antiphospho-IRF3 anti-STAT1, anti-phospho-STAT1, anti-TBK1, and anti-phospho-TBK1 antibodies were obtained from Cell Signaling Technology (Boston, MA, USA), and anti- $\beta$-actin was purchased from Santa Cruz Biotechnology (Santa Cruz, CA, USA). Antibodies against NS-1, PA, HA, PB-1, M2, and M1 were purchased from GeneTex (San Antonio, TX, USA).

\section{Viral Replication Inhibition Assay}

A GFP-based viral replication assay was performed with a GFPtagged IAV as described previously (Talactac et al., 2015). RAW 264.7 cells were cultured in six-well plates $\left(1 \times 10^{6}\right.$ cells/well $)$ for $12 \mathrm{~h}$. Cells were then exposed to a medium (RPMI, negative control), $1000 \mathrm{U}$ recombinant mouse IFN- $\beta$ (positive control), or $100 \mu \mathrm{g} / \mathrm{mL}$ WPS. After $12 \mathrm{~h}$, cells were infected with H1N1GFP [multiplicity of infection $(\mathrm{MOI})=1$ ]. GFP expression was observed under a microscope after $24 \mathrm{~h}$ of virus infection. Cell 
TABLE 1 | Primers sequences for real-time RT-PCR.

\begin{tabular}{lcc}
\hline Name & Orientation & Primer sequences $\mathbf{5}^{\prime}$ to $\mathbf{3}^{\prime}$ orientation \\
\hline GAPDH & Forward & TGACCACAGTCCATGCCATC \\
STAT1 & Feverse & GACGGACACATTGGGGGTAG \\
& Forward & TGGTGAAATGGAAGAGCTG \\
IRF-7 & Forward & CAGACTTCCGTTGGTGGATT \\
& Reverse & AAGCTGGAGCCATGGGTATG \\
IFN-beta & Forward & GACCCAGGTCCATGAGGAAG \\
& Reverse & TCCAAGAAAGGACGAACATTCG \\
ISG-20 & Forward & TGCGGACATCTCCCACGTCAA \\
& Reverse & AGAGATCACGGACTACAGAA \\
& & TCTGTGGACGTGTCATAGAT \\
\hline
\end{tabular}

viability was determined via the MTS or CCK-8 assay (pretreatment method). Additionally, for post-treatment analysis, MDCK cells were seeded onto a 96-well plate and infected with $\mathrm{H} 1 \mathrm{~N} 1$ for $2 \mathrm{~h}$, after which the virus was removed and cells were treated with WPS at 100 or $400 \mu \mathrm{g} / \mathrm{mL}$ for $24 \mathrm{~h}$. The medium was the negative control, and ribavirin $(10 \mu \mathrm{g} / \mathrm{mL})$ was the positive control. Virus-induced cell death was measured by the MTS or CCK-8 assay.

\section{Viral Yield Reduction Assay}

To determine the ability of WPS to inhibit virus-induced red blood cell (RBC) hemolysis, RAW 264.7 cells were seeded in six-well plates at $1 \times 10^{6}$ cells per well and were incubated overnight to reach $70 \%$ confluence. Cells were washed with PBS and infected with H1N1-GFP (MOI = 1). The virus yield reduction assay was performed after $24 \mathrm{~h}$ of incubation with WPS. The medium was the negative control, and IFN- $\beta$ was the positive control. Briefly, $50 \mu \mathrm{L}$ PBS was added to each well of a U-bottomed 96-well plate. The infected supernatant, WPS, IFN- $\beta$, and medium were serially diluted twofold in the previously loaded PBS. Finally, $100 \mu \mathrm{L} 1 \%$ chicken RBCs were added to each well. Assays were evaluated for $1 \mathrm{~h}$ of incubation at room temperature. RBCs in negative wells sedimented and exhibited agglutination, whereas positive wells had an opaque appearance or displayed hemolysis with no sedimentation. Titers are presented in HA units $/ 50 \mu \mathrm{L}$ (HAU/50 $\mu \mathrm{L})$ in comparison with the control treatment (Eisfeld et al., 2014; Abdal Dayem et al., 2015).

\section{Real-time RT-PCR}

Total RNA was extracted using RNeasy Mini Kit (QIAGEN, Valencia, CA, USA) according to the manufacturer's instructions. RNA concentrations were measured using a NanoDrop ND-1000 spectrophotometer (NanoDrop Technologies, Wilmington, DE, USA), and total RNA (1 $\mu \mathrm{g}$ ) was converted to cDNA using RevoScript $^{\text {TM }}$ RT PreMix (iNtRON Biotechnology, Sungnam, Korea). Real-time RT-PCR was performed using the primers listed in Table 1. Reactions were conducted in triplicate with a total volume of $20 \mu \mathrm{L}$ consisting of $0.3 \mu \mathrm{M}$ of each primer, $10 \mu \mathrm{L}$ AccuPower ${ }^{\circledR}$ 2X Greenstar qPCR Master Mix (Bioneer, Daejeon, Korea), and $2 \mu \mathrm{L}$ template DNA. Amplification and analyses were performed using QuantStudio 6 Flex Real-Time PCR System (Thermo Scientific). Relative expression was calculated using the $\Delta \Delta \mathrm{Ct}$ method. Individual transcripts in each sample were assayed three times and normalized to GADPH mRNA levels.

\section{Hemagglutination Assay}

WPS was diluted $(1-1000 \mu \mathrm{g} / \mathrm{mL})$ with PBS in a round-bottomed 96-well plate. The medium was used as a negative control. H1N1, H1N1-GFP, or H3N2 (64 HAUs in PBS) was added to each well and incubated for $30 \mathrm{~min}$ at $37^{\circ} \mathrm{C}$ under $5 \% \mathrm{CO}_{2}$. Each sample was mixed with $1 \%$ chicken RBCs (Innovative Research, Inc., Southfield, MI, USA) in PBS. After incubation for $1 \mathrm{~h}$ at room temperature, plates were photographed.

\section{NA Inhibition Assay}

WPS was used at $1-2000 \mu \mathrm{g} / \mathrm{mL}$. Zanamivir, a specific NA blocker, was used as a control at $0.001-10 \mu \mathrm{g} / \mathrm{mL}$. The NA inhibition assay was performed according to the manufacturer's instructions using the NA-Fluor Influenza Neuraminidase Assay kit (Life Technologies, Carlsbad, CA, USA). The reaction was monitored using a fluorescence spectrometer in the kinetic mode at an excitation wavelength of $365 \mathrm{~nm}$ and emission wavelength of $445 \mathrm{~nm}$ (Abdal Dayem et al., 2015).
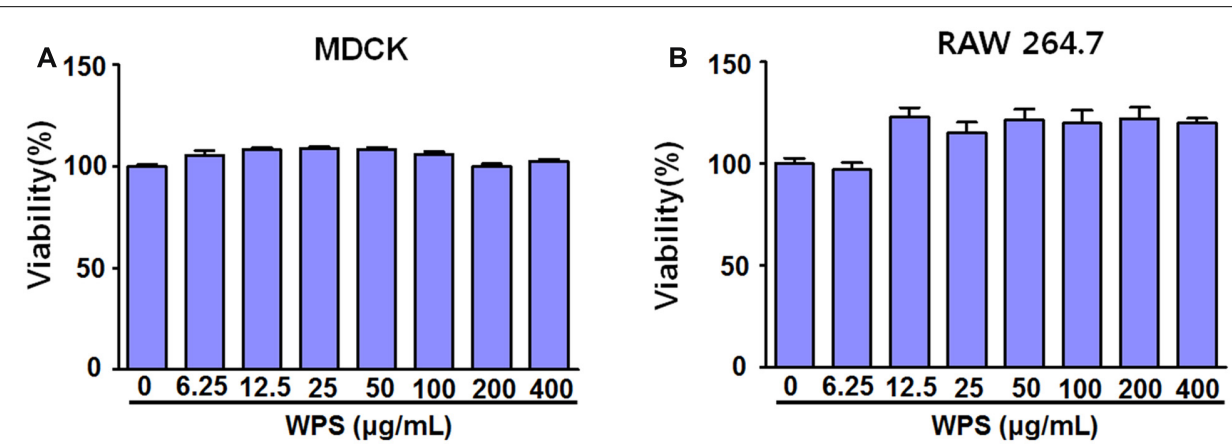

FIGURE 1 | Determination of the effective cytotoxic concentration of the water extract of Psoraleae semen (WPS) in (A) MDCK and (B) RAW 264.7 cells. The indicated concentrations of WPS were added to MDCK and RAW 264.7 cells. Cell viabilities were determined by the CCK-8 or MTS assay after 24 h $(n=3$ each). Data are representative of three independent experiments. 


\section{A Protocol}

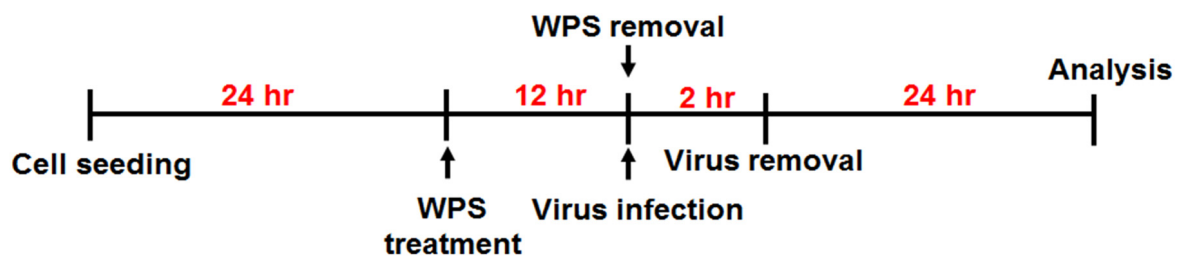

B
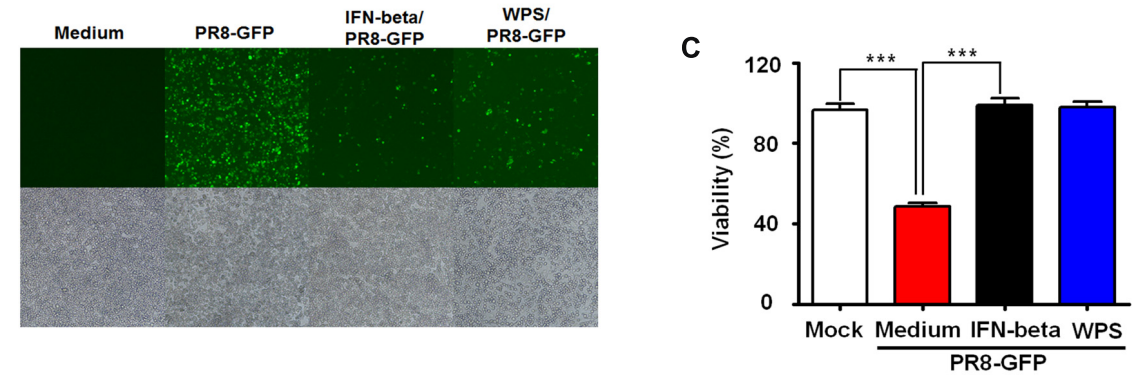

D
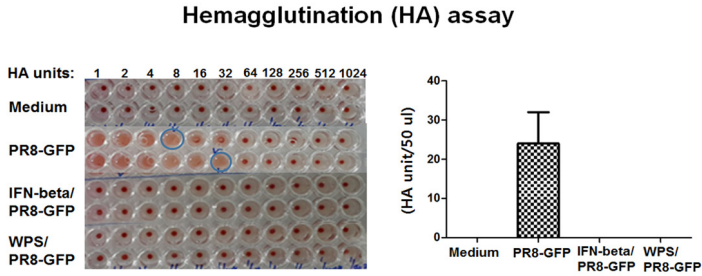

FIGURE 2 | Anti-viral activities of pre-treatment with WPS on the influenza A/PR/8/34 (H1N1)-GFP virus in RAW 264.7 cells. (A) RAW 264.7 cells were treated with WPS prior to influenza A virus infection. (B) Cells incubated with the medium alone, $100 \mu \mathrm{g} / \mathrm{mL}$ WPS, or $1000 \mathrm{U} / \mathrm{mL}$ interferon- $\beta$ (recombinant $\mathrm{mouse}$ ) $12 \mathrm{~h}$ prior to infection with H1N1-GFP (multiplicity of infection = 1). Images of GFP expression were obtained $24 \mathrm{~h}$ after virus infection $(\mathbf{C})$ Cell viability was determined $24 \mathrm{~h}$ after virus infection by the MTS or CCK 8 assay, and survival is presented as a percentage of the control value (cells without treatment). Data are presented as the mean \pm SD (error bars) of three independent experiments. ${ }^{* * *} P<0.0005$ indicates a significant difference between groups. (D) Viruses were titrated from the supernatant via the hemagglutination assay. Error bars indicate the range of values obtained from two independent experiments.

\section{Western Blot Analysis}

Total protein expression of whole cell extracts or cytoplasmic and nuclear extracts was determined using Bradford reagent (Bio-Rad, Hercules, CA, USA). Equal protein amounts were resolved on sodium dodecyl sulfate gels by polyacrylamide gel electrophoresis and transferred to PVDF membranes. After blocking non-specific sites with 5\% skim milk, membranes were incubated with each primary (1:1000 dilution) and secondary (1:2000 dilution) antibody, and expression was detected using SuperSignal West Femto Chemiluminescent Substrate (Thermo Scientific). Relative band intensity was measured using ImageJ.

\section{Enzyme-Linked Immunosorbent Assay}

Murine IL-6, TNF- $\alpha$, and IL- $1 \beta$ levels in culture supernatants were determined using enzyme-linked immunosorbent assay antibody kits (eBioscience, San Diego, CA, USA) according to the manufacturer's instructions.

\section{Immunocytochemistry}

RAW 264.7 cells $\left(0.5-1.0 \times 10^{5}\right)$ grown on a four-well tissue culture slide were cultured at $37^{\circ} \mathrm{C}$ for $24 \mathrm{~h}$. For pre-treatment, WPS $(100 \mu \mathrm{g} / \mathrm{mL})$ was added to cells, which were incubated in a $\mathrm{CO}_{2}$ incubator at $37^{\circ} \mathrm{C}$ for $12 \mathrm{~h}$. After WPS treatment, the medium was discarded, and cells were washed with PBS and infected with H1N1 (MOI = 1) for $2 \mathrm{~h}$. After infection, the medium was discarded and cells were washed with PBS; the medium was then added to cells, which were incubated in a $\mathrm{CO}_{2}$ incubator at $37^{\circ} \mathrm{C}$ for $24 \mathrm{~h}$. For post-treatment with WPS, cells were infected with $\mathrm{H} 1 \mathrm{~N} 1$ (MOI = 1) for $2 \mathrm{~h}$. After infection, the medium was discarded, and cells were washed with PBS. Next, WPS was added to cells, which were incubated in a $\mathrm{CO}_{2}$ incubator at $37^{\circ} \mathrm{C}$ for $24 \mathrm{~h}$. At $24 \mathrm{~h}$ post-infection, cells were washed with PBS three times and fixed with $4 \%$ paraformaldehyde for $30 \mathrm{~min}$ and $1 \%$ Triton X-100 at room temperature. After blocking, fixed cells were incubated with an M2-specific antibody overnight, washed with TBS three times, and incubated with Alexa Fluor 568-goat anti-rabbit IgG antibody (1:1000; Life Technologies, 
A
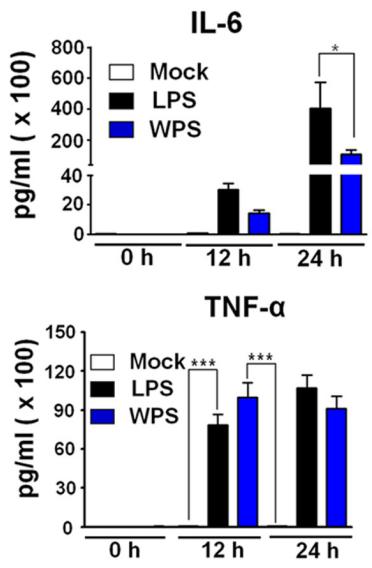

IFN-beta

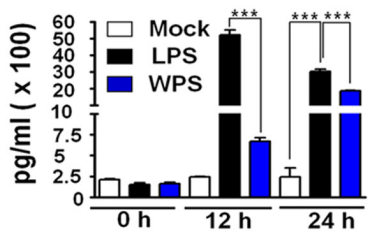

B

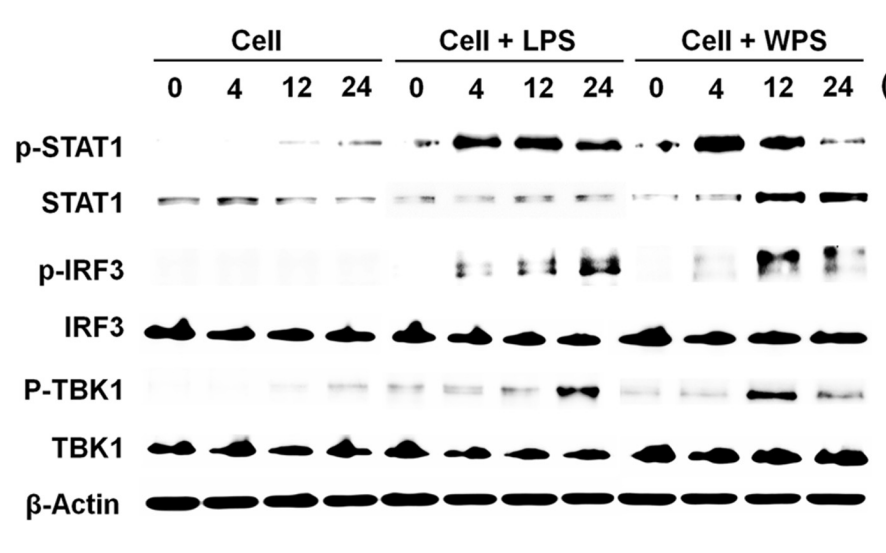

C

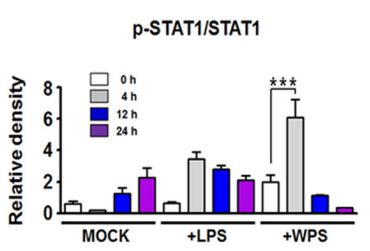

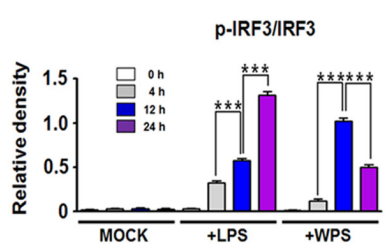

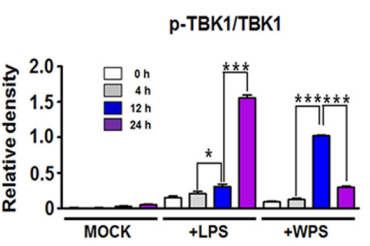

FIGURE 3 | Stimulation of an anti-viral state by WPS in RAW $\mathbf{2 6 4 . 7}$ cells. Cells were treated with the medium alone (mock), 100 ng/mL lipopolysaccharides, or $100 \mu \mathrm{g} / \mathrm{mL}$ WPS and were then incubated at $37^{\circ} \mathrm{C}$ and $5 \% \mathrm{CO}_{2}$. Cells treated with the medium served as the negative controls. The supernatant from each group was harvested at 0,12 , and $24 \mathrm{~h}$ and clarified by centrifugation at $3500 \mathrm{rpm}$ for $20 \mathrm{~min}$ at $4^{\circ} \mathrm{C}$. (A) The cytokines (IL-6, TNF- $\alpha$, and IFN- $\beta$ ) secreted in treated RAW 264.7 cells were measured by an enzyme-linked immunosorbent assay using antibody-coated enzyme-linked immunosorbent assay plates. The test was performed in triplicate. The data show representative means \pm SDs of each murine cytokine measured over time from three independent assays. Asterisks indicate a significant difference between groups (***P $\left.<0.0005,{ }^{*} P<0.05\right)$. (B,C) Immunoblot analysis was performed using the lysates of RAW 264.7 cells treated with or without WPS to assess the expression of the phosphorylated and non-phosphorylated forms of STAT1, IRF3, TBK1, and $\beta$-actin over time. The experiment was repeated three times independently, and similar results were obtained. ${ }^{* * *} P<0.0005,{ }^{*} P<0.05$ compared with the mock value.

Eugene, OR, USA) for $1 \mathrm{~h}$ at $25^{\circ} \mathrm{C}$. Next, cells were incubated with DAPI for 10 min and observed by fluorescence microscopy.

\section{High-Performance Liquid Chromatography (HPLC) Analysis}

Water extract of PS standardization was performed by HPLC fingerprinting with chemical standards purchased from ChemFaces (psoralen, angelicin, bavachin, and bavachinin; Wuhan, Hubei, China). Standard solutions were prepared by dissolving each marker component in 100\% methanol at $1 \mathrm{mg} / \mathrm{mL}$. WPS powder was accurately weighed and dissolved in methanol at $10 \mathrm{mg} / \mathrm{mL}$ for analysis. HPLC-grade acetonitrile was purchased from Merck (Darmstadt, Germany), and acid was purchased from Sigma-Aldrich. Separation was performed in a Dionex HPLC system (Dionex Co., Sunnyvale, CA, USA) equipped with an ultimate 3000 series A binary pump, an autosampler, a column oven, and a diode array UV/VIS detector. Data analysis was performed using Dionex Chromeleon. All chromatographic separations were performed on Acclaim C18 $\left(4.6 \times 250 \mathrm{~mm}^{2}, 5 \mu \mathrm{m}\right.$, Dionex $)$ at $30^{\circ} \mathrm{C}$. HPLC analysis was performed in accordance with the methods reported by Zhao et al. (2005) with some modifications. Briefly, the mobile phase consisted of water containing (A) $0.1 \%$ acetic acid and (B) acetonitrile with gradient elution at a flow rate of $1 \mathrm{~mL} / \mathrm{min}$.
Gradient elution was performed as follows: $40-50 \%(\mathrm{v} / \mathrm{v}) \mathrm{B}$ at $0-15 \mathrm{~min}, 50-60 \% \mathrm{~B}$ at $15-35 \mathrm{~min}, 60-70 \% \mathrm{~B}$ at $35-45 \mathrm{~min}$, $70-80 \% \mathrm{~B}$ at $45-55 \mathrm{~min}$, and $80 \% \mathrm{~B}$ at $55-60 \mathrm{~min}$. The injection volume was $10 \mu \mathrm{L}$, and detection wavelength was $245 \mathrm{~nm}$.

\section{Statistics}

All data are presented as mean \pm SD of at least three independent experiments. Statistical significance of mean values in the two groups or treatment effects were evaluated via one-way ANOVA with Dunnett's test. Analyses were performed using GraphPad PRISM software ${ }^{\circledR}$ (GraphPad PRISM software Inc., Version 5.02, La Jolla, CA, USA). Values of ${ }^{*} P<0.05,{ }^{* *} P<0.005$, and ${ }^{* * *} P<0.0005$ indicated statistical significance.

\section{RESULTS}

\section{Effects of WPS on Cell Viability}

WPS cytotoxicities in RAW 264.7 and MDCK cells were evaluated using the CCK-8 assay after $24 \mathrm{~h}$ treatment to determine the optimal concentration that would provide antiviral activity with minimum toxicity. The results illustrated that WPS concentrations of $\leq 400 \mu \mathrm{g} / \mathrm{mL}$ had no significant effects on 
A

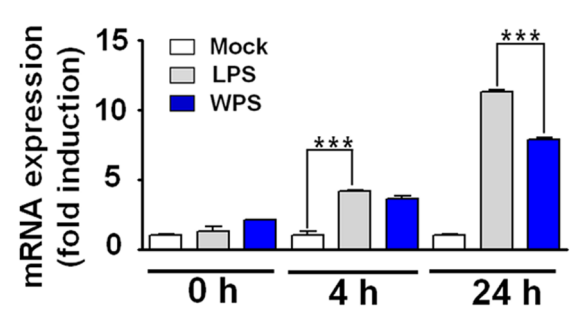

B

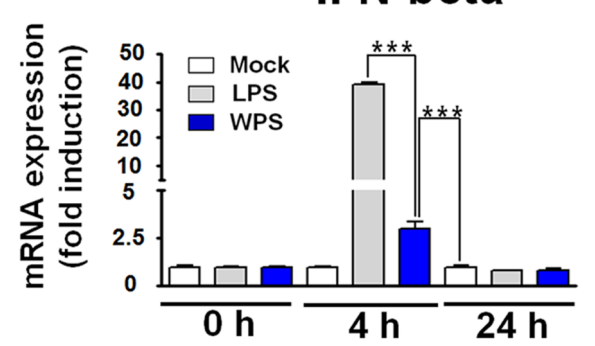

STAT1

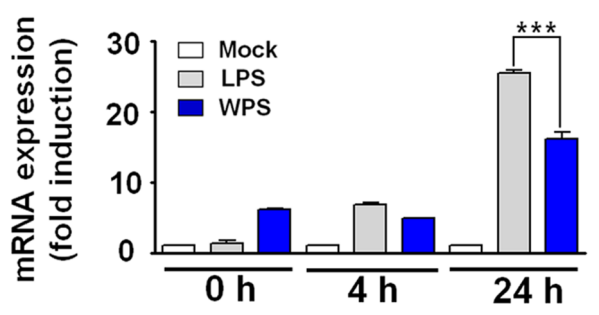

ISG-20

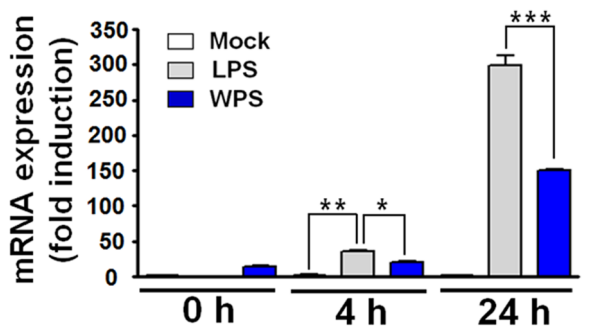

FIGURE 4 | Induction of interferon (IFN)-related gene and IFN-stimulating gene (ISG) transcripts by WPS in RAW 264.7 cells. Cells were treated with the medium alone (mock), $100 \mathrm{ng} / \mathrm{mL}$ lipopolysaccharides, or $100 \mu \mathrm{g} / \mathrm{mL}$ WPS and were then incubated at $37^{\circ} \mathrm{C}$ with $5 \% \mathrm{CO}_{2}$. The time-dependent changes in $\mathrm{mRNA}$ expression (A,B; STAT1, IFN- $\beta$, IRF-7, and ISG-20) were examined after treatment in RAW 264.7 cells. ${ }^{* * *} P<0.0005$, ${ }^{* *} P<0.005$, and ${ }^{*} P<0.05$ compared with the mock value.

cell viability, indicating that WPS was not toxic to RAW 264.7 and MDCK cells (Figures 1A,B). Therefore, subsequent experiments were performed using concentrations of $\leq 100 \mu \mathrm{g} / \mathrm{mL}$.

\section{WPS Increased RAW 264.7 Cell Survival}

To evaluate anti-influenza virus activity of WPS, viral replication using GFP-expressing viruses was examined in cells pre-treated with WPS (Figure 2A). H1N1-GFP-infected RAW 264.7 cells with pre-treated WPS exhibited markedly reduced GFP expression compared to that in the untreated group (Figure 2B). Figure 2C shows that cell death significantly decreased in WPStreated cells compared with that in the virus-only group within $24 \mathrm{~h}$ of H1N1-GFP infection. We found that viral supernatant titers of H1N1-GFP-, IFN-beta/H1N1-GFP-, and WPS/H1N1GFP-infected cells were significantly reduced by WPS or IFN- $\beta$ treatment (0 HAUs) compared to that in the virus-only group (64 HAUs; Figure 2D). These results illustrate that WPS pretreatment reduced H1N1-GFP replication in RAW 264.7 cells.

\section{WPS Induced IFN- $\beta$ and Pro-inflammatory Cytokine Secretion and Type I IFN Signaling Pathway Activation in RAW 264.7 Cells}

The anti-viral response of WPS may be related to the innate immune response through the expression of cytokines, such as IL- 6 and IFN- $\beta$. To correlate these observations with the IFNinducing signaling pathway, we examined the phosphorylation of interferon-related signaling molecules. For elucidating the possible mechanism by which WPS inhibited viral replication, we first measured secreted cytokine levels (IFN- $\beta$, IL-6, and TNF- $\alpha$ ) in treated and untreated virus-infected RAW 264.7 cells. As shown in Figure 3A, WPS induced high levels of IL-6, TNF- $\alpha$, and IFN- $\beta$ secretion (Figure 3A) after $24 \mathrm{~h}$ compared to levels in medium- or lipopolysaccharide-treated positive controls. The results indicate that IL-6, TNF- $\alpha$, and IFN- $\beta$ can be induced by WPS, thus mediating the anti-viral state in RAW 264.7 cells. In addition, the anti-viral effect of WPS may be related to the innate immune response through cytokine expression, such as IFN- $\beta$ and IL- 6 . To correlate the aforementioned observations with the IFN signaling pathway, we examined the effects of WPS on type I IFN-related protein phosphorylation. For this purpose, whole cell lysates of WPS-treated RAW 264.7 cells were subjected to immunoblotting to analyze the expression of the phosphorylated and non-phosphorylated forms of STAT1, IRF3, and TBK1. As shown in Figure 3B, WPS treatment in RAW 264.7 cells upregulated phosphorylation of STAT1, IRF-3, and TBK1, which are important molecules in the type I IFN signaling pathway (Trinchieri, 2010). IRF3 phosphorylation indicates IRF3 molecule translocation into the nucleus and transcription initiation of type I IFNs. Consequently, the produced type I IFNs bind to proteins in JAK-STAT pathway (Horvath, 2004; Trinchieri, 2010), leading to the phosphorylation of STAT1 and transcriptional activation of interferon-stimulating genes (ISGs). Our results indicate that WPS treatment induces IRF3, STAT1, and TBK1 phosphorylation at $12 \mathrm{~h}$ to levels compared to findings in untreated cells (Figures 3B and 2C). 


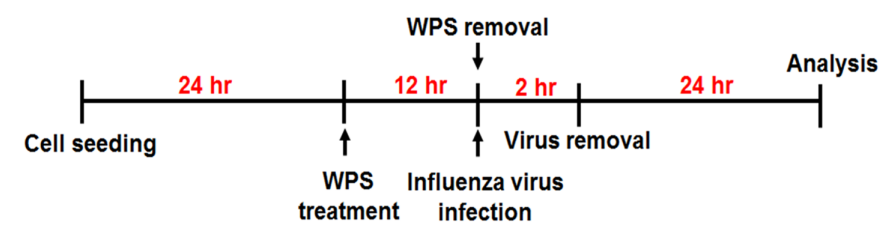

Post-treatment protocol
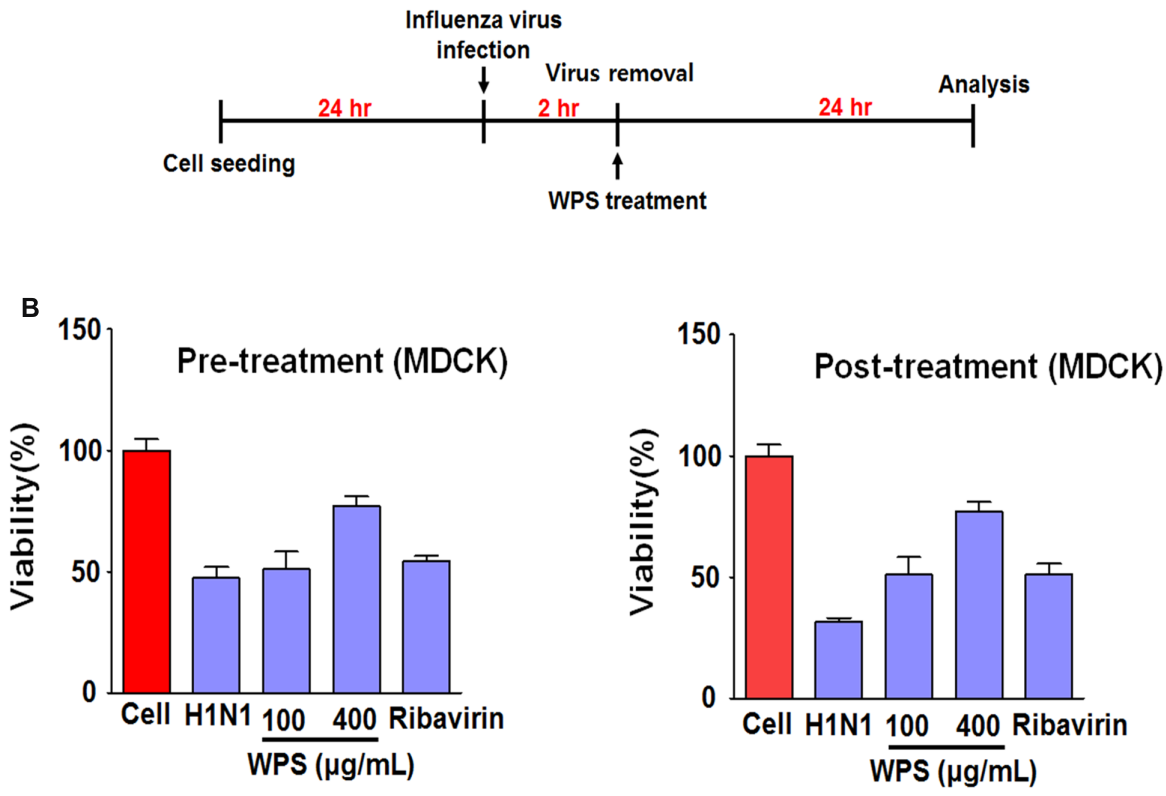

FIGURE 5 | WPS inhibited influenza A/PR/8/34 (H1N1) infection in MDCK cells. (A) MDCK cells were treated with WPS before or after viral adsorption. (B) Cells were incubated with the medium alone (mock), $100 \mu \mathrm{g} / \mathrm{mL}$ WPS, or $10 \mu \mathrm{g} / \mathrm{mL}$ ribavirin before or after infection with H1N1-GFP (multiplicity of infection = 1). Cell viability was determined $24 \mathrm{~h}$ after viral infection by the MTS or CCK 8 assay, and survival is presented as a percentage of the control value (untreated cells). Data are presented as the mean \pm SD (error bars) of three independent experiments.

We further confirmed the interaction between WPS and IFN-stimulated gene induction in RAW 264.7 cells. A timedependent increase in the mRNA expression of STAT1, IRF-7, IFN- $\beta$, and ISG-20 was observed in WPS-treated RAW 264.7 cells compared with levels in untreated cells (Figure 4A). In addition, upregulation of IFN- $\beta$ and ISG was noted at $24 \mathrm{~h}$. The observed pattern was similar to that of lipopolysaccharide-treated positive control (Figure 4A), and transcription of IRF-7 and ISG20 increased by 16- and 150-fold, respectively. The overall results suggest that WPS induces the anti-viral state by modulating the IFN signaling pathway and IRF-7 and ISG-20 expression in RAW264.7 cells, which may result in viral replication inhibition (Espert et al., 2005; Lazear et al., 2013; Sheikh et al., 2014).

\section{WPS Inhibited H1N1 Infection in MDCK Cells}

To investigate whether WPS inhibited IAV infection in MDCK cells, we examined viral replication in MDCK cells treated with WPS before and after infection with H1N1 (Figure 5A). WPSpre-treated and WPS-post-treated (100 and $400 \mu \mathrm{g} / \mathrm{mL}$ ) cells displayed significantly decreased cell death compared to that in cells exposed only to H1N1 (Figure 5B), indicating that both preand post-treatment with WPS reduces viral replication in MDCK cells.

\section{WPS Reduced H1N1 Viral Protein Expression}

To evaluate whether WPS inhibited H1N1 viral protein expression, we performed Western blotting in RAW 264.7 cells treated with WPS before and after H1N1 infection. Relative protein expression levels of viral proteins (PA, HA, PB-1, M2, M1) as analyzed by Western blotting were significantly lower in RAW 264.7 cells with pre- or post-treatment of WPS than in those treated with the medium alone (Figures 6A,B). WPS pre-treatment decreased M1, M2, and PB1 levels by 0.8-, 0.9-, and 0.9-fold, respectively. Post-treatment with WPS decreased M1, HA, and PB1 levels by 0.9-, 0.4-, and 0.9fold, respectively (Figures 6C,D). Further, we demonstrated, by immunofluorescent analysis, that M2 protein levels significantly decreased in RAW 264.7 cells treated with WPS before and 
A

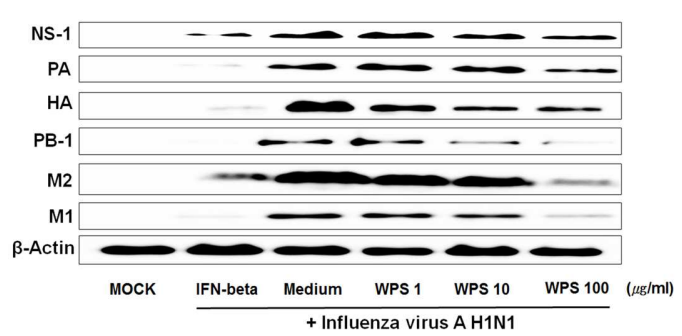

C
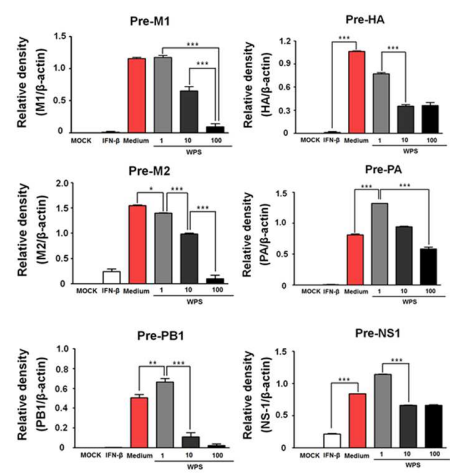

E

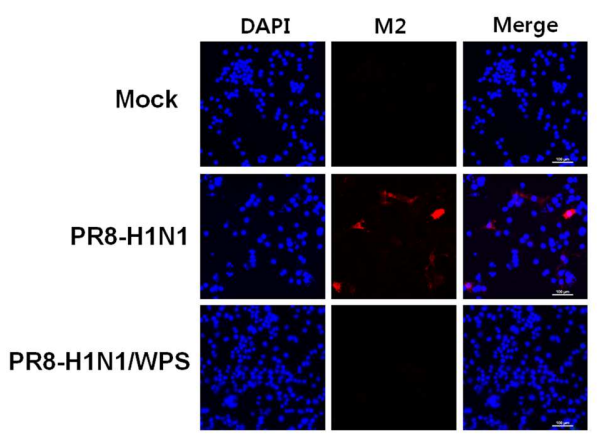

B

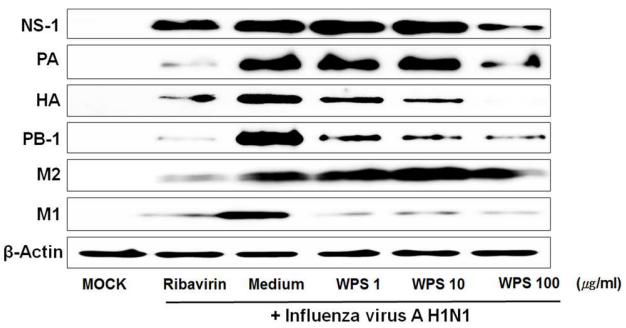

D
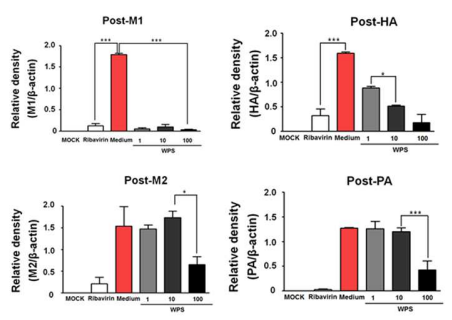

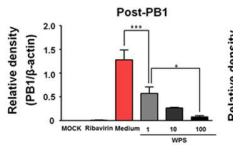

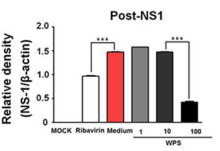

$\mathbf{F}$

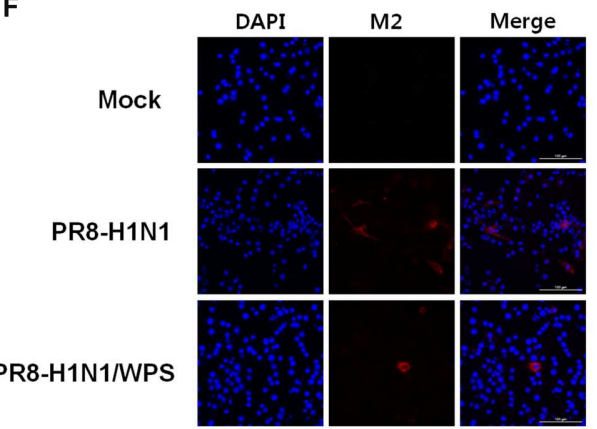

FIGURE 6 | WPS inhibited influenza A/PR/8/34 (H1N1) protein expression in RAW 264.7 cells. RAW 264.7 cells were treated with WPS (100 $\mu$ g/mL), interferon (IFN)- $\beta(1000 \mathrm{U} / \mathrm{mL}$, recombinant mouse, pre-treatment positive control), ribavirin (10 $\mu \mathrm{g} / \mathrm{mL}$, post-treatment positive control), or the medium only (negative control) before (A,C) or after (B,D) after viral adsorption. Influenza A virus protein levels (NS-1, PA, HA, PB-1, M1, M2) in cell lysates were analyzed by Western blotting, and $\beta$-actin expression was analyzed as an internal control. Data are presented as the mean \pm SD (error bars) and are representative of three independent experiments. ${ }^{* *} \mathrm{P}<0.0005,{ }^{*} \mathrm{P}<0.005,{ }^{*} \mathrm{P}<0.05$ compared with the mock value. RAW 264.7 cells were infected with $\mathrm{H} 1 \mathrm{~N} 1$ (multiplicity of infection $=1$ ) before $(\mathbf{E})$ or after WPS treatment $(\mathbf{F})$. Cells were observed by fluorescence microscopy using an M2-specific antibody. The cells were also stained with DAPI. The merged image illustrates the cytoplasmic localization of viral M2 (red) and selected nuclei (DAPI, blue).

after $\mathrm{H} 1 \mathrm{~N} 1$ exposure compared with levels in untreated cells (Figures 6E,F). Therefore, these data revealed that pre- and posttreatment with WPS reduced $\mathrm{H} 1 \mathrm{~N} 1$ virus protein expression.

\section{Inhibitory Effects of WPS on NA Activity}

$\mathrm{NA}$ is a key viral protein responsible for releasing newly produced virus particles and the recognition and cleavage of target cell receptor sialic acid moieties (N-acetylneuraminic acid) on infected cells (Chazal and Gerlier, 2003). Additionally, NA activity is required for preventing the self-aggregation of virus particles via the cleavage of sialic acids bound to the virus surface. We therefore tested the potential effect of WPS on viral NA activity. NA activity from H1N1-GFP and H1N1-WT decreased significantly with WPS and zanamivir used as the positive control (Figure 7A). Moreover, WPS (1000 $\mu \mathrm{g} / \mathrm{mL})$ treatment had a significantly suppressive effect on NA activity for $\mathrm{H} 3 \mathrm{~N} 2$ (37.5\%) and H1N1-WT (30\%). The results suggest that WPS has additional inhibitory effects on the IAV release step through inhibiting NA, particularly at high concentrations.

\section{Inhibitory Effects of WPS on Virus Adsorption}

IAVs can induce hemagglutination in RBCs. Therefore, we investigated whether WPS alters viral adsorption onto RBCs, 
A
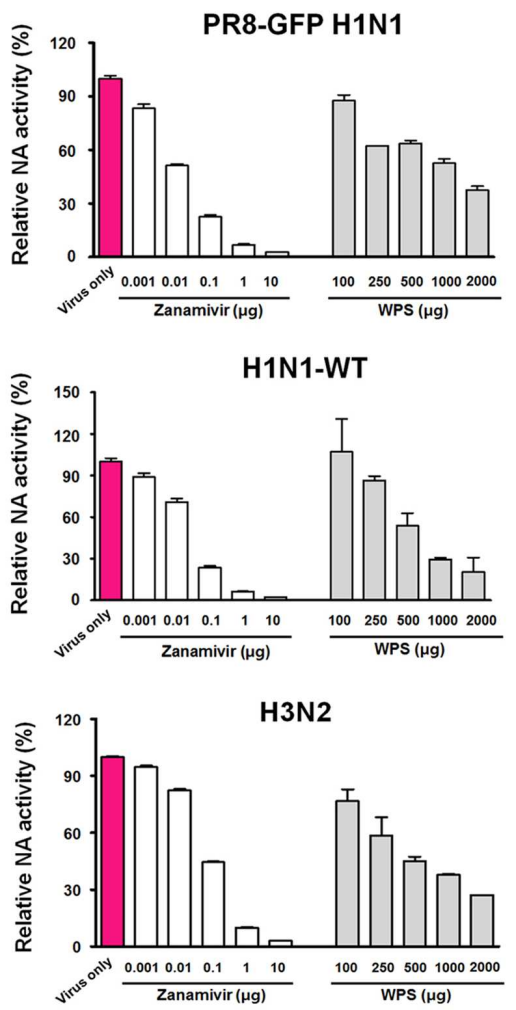

B Hemagglutination assay(HA)
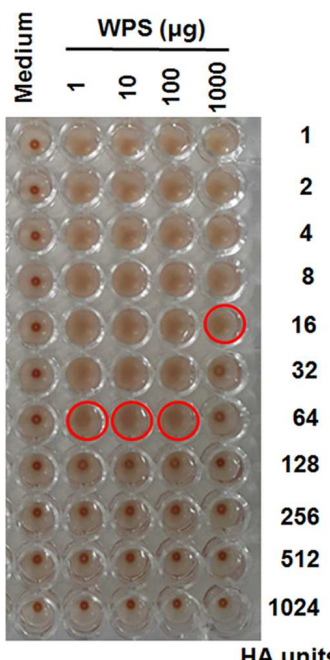

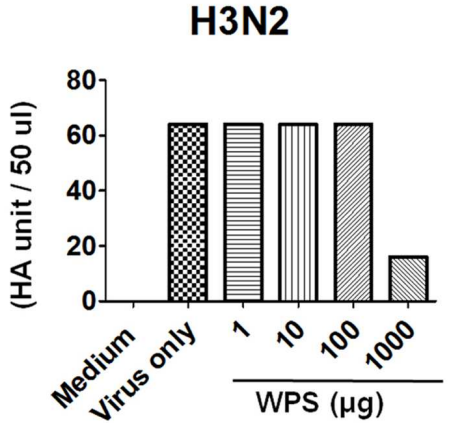

FIGURE 7 | Measurement of the anti-viral activity of WPS using neuraminidase inhibition and hemagglutination inhibition assays. (A) Influenza A viruses ( $\mathrm{H} 1 \mathrm{~N} 1$ and $\mathrm{H} 3 \mathrm{~N} 2$ ) were added at 32 hemagglutination units (HAUs) to the indicated concentrations of WPS, zanamivir (positive control), or PBS (negative control); were mixed with NA-Fluor ${ }^{\mathrm{TM}}$ substrate; and were incubated at $37^{\circ} \mathrm{C}$ for $1 \mathrm{~h}$ away from light. Fluorescence was monitored (excitation, $365 \mathrm{~nm}$; emission, $445 \mathrm{~nm}$ ). Data are representative of two independent experiments, and results were reproducible. (B) Hemagglutination inhibition assay: WPS was serially diluted using PBS and added to equal volumes of the viruses (64 HAUs). To assess red blood cell (RBC) hemolysis inhibition, $50 \mu \mathrm{L} 1 \%$ chicken RBCs were added to each well of a 96-well plate and incubated for $1 \mathrm{~h}$ at room temperature. Data are representative of two independent experiments, and results were reproducible.

resulting in hemagglutination. WPS decreased H3N2 viral titers by twofold in the HA assay (Figure 7B). However, WPS treatment did not inhibit RBC hemolysis in H1N1-infected cells (data not shown). These results suggest that the potent hemagglutinationinhibiting activity of WPS is attributed to a direct interaction with $\mathrm{H} 3 \mathrm{~N} 2$, particularly at high concentrations.

\section{HPLC Analysis of WPS}

The UV wavelength of chromatograms was adjusted on the basis of the maximum UV absorption wavelengths of the following major standard compounds: psoralen, $246 \mathrm{~nm}$; angelicin, $248 \mathrm{~nm}$; bavachin, $237 \mathrm{~nm}$; and bavachinin, $237 \mathrm{~nm}$; therefore, the analysis was performed at $245 \mathrm{~nm}$. WPS constituents were determined by HPLC-diode array detection analysis, and each peak of the UV spectra was compared with that of representative standard compounds. As shown in Figure 8, HPLC-diode array detection analysis revealed a single peak specific for chemicals contained in WPS extracts at the following retention times: psoralen, $10.03 \mathrm{~min}$; angelicin, $10.74 \mathrm{~min}$; bavachin, $19.36 \mathrm{~min}$; and bavachinin, $35.52 \mathrm{~min}$. The following values were observed for the standard compounds: psoralen, $10.02 \mathrm{~min}$; angelicin,
$10.73 \mathrm{~min}$; bavachin, $19.36 \mathrm{~min}$; and bavachinin, $35.52 \mathrm{~min}$ (Figure 8).

\section{DISCUSSION}

Herbal medicines have gained popularity to control viral and bacterial infections; they have a low incidence of side effects (Martin and Ernst, 2003; Ehrhardt et al., 2007; Ge et al., 2010). Herbal extracts have anti-influenza effects (He et al., 2011; Haruyama and Nagata, 2013; Makau et al., 2013). In the present study, we demonstrated that WPS protects against infection by IAV subtypes in MDCK and RAW 264.7 cells. Psoralen and bakuchiol are the dominant compounds in WPS, and they have anti-viral activity against many viruses such as influenza and herpes simplex viruses (Nakashima et al., 1979; Redfield et al., 1981). Recently, bakuchiol was found to exert anti-influenza viral activity via Nrf2 activation (Shoji et al., 2015). However, no detailed mechanism has been described for the immunoregulatory and immune enhancing effects of WPS. Nevertheless, we were unable to define the mechanism of the anti-viral effects of WPS. WPS sufficiently protected against 

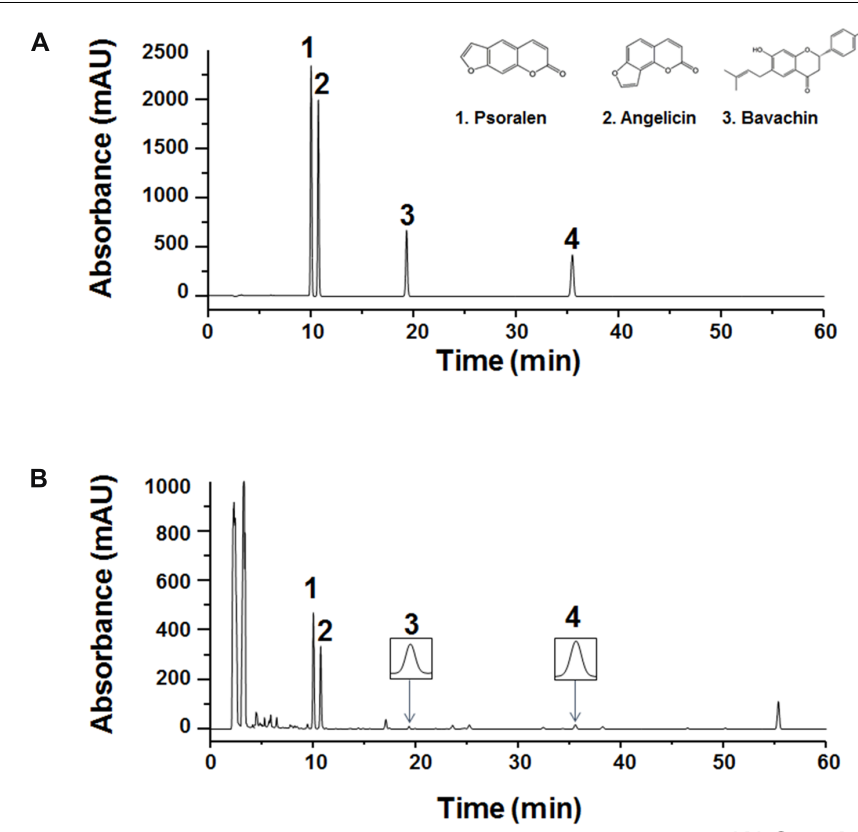

(A) Standard compound : $245 \mathrm{~nm}$ (B) WPS $20 \mathrm{mg} / \mathrm{ml} \quad: 245 \mathrm{~nm}$

FIGURE 8 | Measurement of the representative component in WPS by high-performance liquid chromatography. Psoralen (1), angelicin (2), bavachin (3), and bavachinin (4) were identified in the standard mixture (A) and WPS (B) at a wavelength of $245 \mathrm{~nm}$. Data are representative of three independent experiments, and results were reproducible (Supplementary Figure 1).

viral replication by modulating the innate immune response and inducing an anti-viral state. Moreover, we found that WPS enhanced the survival of IAV-infected MDCK and RAW 264.7 cells and inhibited influenza A viral infection and growth as well as viral protein expression (Figures 2 and 6). Innate immune cells, such as macrophages, initially recognize viral infections and rapidly induce the production of type I IFNs and proinflammatory cytokines, thereby generating anti-viral immune responses. We hypothesize that WPS induces an anti-viral state in murine macrophage cells by inducing anti-viral cytokines, modulating immune response, and inhibiting viral replication. Thus, we determined that type I IFN and IFN-stimulated gene levels (Figures 3 and 4) were altered in WPS-pre-treated RAW 264.7 cells. The effects of WPS on the phosphorylation of type I IFN signaling proteins, such as IRF3, TBK1, and STAT1, were examined in extract-treated RAW 264.7 cells. Type I IFNs upregulate the anti-viral status of infected cells (Sharma et al., 2003; Chiu et al., 2009). In our study, we found that WPS pretreatment induced IRF3, TBK1, and STAT1 phosphorylation, thereby providing evidence of the downstream activation of signaling molecules in the type I IFN pathway.

This is the first study reporting that WPS possesses antiinfluenza activity. We found that WPS chirality is important for this activity; thus, WPS should be considered a novel anti-H1N1 or -H3N2 drug. Our pre-incubation experiment illustrated that WPS more strongly inhibited H3N2 strains than H1N1 strains in HA and NA inhibition assays (Figure 7). This may reflect strainassociated differences in HA and NA viral proteins between the $\mathrm{H} 3 \mathrm{~N} 2$ and H1N1 strains, or the host cell response.

\section{CONCLUSION}

We found that WPS can be a significant alternative anti-viral therapeutic agent for disrupting viral infection through the activation of type I IFN-mediated signaling, thereby inducing an anti-viral state in RAW 264.7 cells. Moreover, the antiinfluenza effects of WPS are mediated by direct HA and NA inhibition. However, this study demonstrated that WPS had anti-viral activity only under in vitro conditions. Therefore, extensive future investigations for evaluating the potential of WPS for in vivo anti-viral therapeutic applications are warranted. An important step in this direction will be the identification of individual anti-viral agents from WPS and the analysis of their pharmacokinetic properties. In addition, specific signaling pathways and adequate dosage and efficacy duration of the extract in the host should be examined. The study results suggest that WPS has anti-viral activity against the influenza A subtypes $\mathrm{H} 1 \mathrm{~N} 1$ and $\mathrm{H} 3 \mathrm{~N} 2$. Our findings describe a possible mechanism of action of the anti-viral effects of WPS involving type I IFN signaling pathway activation and direct HA and NA inhibition. Thus, our results indicate that WPS has the potential to be an effective herbal remedy for the prophylaxis and treatment of influenza virus infection.

\section{AUTHOR CONTRIBUTIONS}

JYM and WKC developed the study design and revised the paper. JGC participated in the study design, performed the experiments, 
analyzed the data, and wrote the draft. YHJ, JHK, and TWO participated in the study design and analyzed the data. NHY conducted HPLC analysis. All authors have read and approved the final version of paper.

\section{FUNDING}

This work was supported by Grant K16281 awarded to Korea Institute of Oriental Medicine (KIOM) from Ministry of Education, Science and Technology (MEST), Korea.

\section{REFERENCES}

Abdal Dayem, A., Choi, H. Y., Kim, Y. B., and Cho, S. G. (2015). Antiviral effect of methylated flavonol isorhamnetin against influenza. PLoS ONE 10:e 0121610. doi: 10.1371/journal.pone.0121610

Anderson, K. V. (2000). Toll signaling pathways in the innate immune response. Curr. Opin. Immunol. 12, 13-19. doi: 10.1016/S0952-7915(99)00045-X

Bouvier, N. M., Lowen, A. C., and Palese, P. (2008). Oseltamivir-resistant influenza A viruses are transmitted efficiently among guinea pigs by direct contact but not by aerosol. J. Virol. 82, 10052-10058. doi: 10.1128/JVI.01226-08

Capua, I., and Alexander, D. J. (2004). Human health implications of avian influenza viruses and paramyxoviruses. Eur. J. Clin. Microbiol. Infect. Dis. 23, 1-6. doi: 10.1007/s10096-003-1059-3

Centers for Disease and Prevention (2006). High levels of adamantane resistance among influenza A (H3N2) viruses and interim guidelines for use of antiviral agents-United States, 2005-06 influenza season. MMWR Morb. Mortal. Wkly. Rep. 55, 44-46.

Chazal, N., and Gerlier, D. (2003). Virus entry, assembly, budding, and membrane rafts. Microbiol. Mol. Biol. Rev. 67, 226-237. doi: 10.1128/MMBR.67.2.226-237. 2003

Chiu, Y. H., Macmillan, J. B., and Chen, Z. J. (2009). RNA polymerase III detects cytosolic DNA and induces type I interferons through the RIG-I pathway. Cell 138, 576-591. doi: 10.1016/j.cell.2009.06.015

Cho, W. K., Weeratunga, P., Lee, B. H., Park, J. S., Kim, C. J., Ma, J. Y., et al. (2015). Epimedium koreanum Nakai displays broad spectrum of antiviral activity in vitro and in vivo by inducing cellular antiviral state. Viruses 7, 352-377. doi: $10.3390 / \mathrm{v} 7010352$

Cowan, M. M. (1999). Plant products as antimicrobial agents. Clin. Microbiol. Rev. $12,564-582$.

Ehrhardt, C., Hrincius, E. R., Korte, V., Mazur, I., Droebner, K., Poetter, A., et al. (2007). A polyphenol rich plant extract, CYSTUS052, exerts anti influenza virus activity in cell culture without toxic side effects or the tendency to induce viral resistance. Antiviral Res. 76, 38-47.

Eisfeld, A. J., Neumann, G., and Kawaoka, Y. (2014). Influenza A virus isolation, culture and identification. Nat. Protoc. 9, 2663-2681. doi: 10.1038/nprot.2014. 180

Espert, L., Degols, G., Lin, Y. L., Vincent, T., Benkirane, M., and Mechti, N. (2005). Interferon-induced exonuclease ISG20 exhibits an antiviral activity against human immunodeficiency virus type 1. J. Gen. Virol. 86, 2221-2229. doi: 10.1099/vir.0.81074-0

Fiore, A. E., Bridges, C. B., and Cox, N. J. (2009). Seasonal influenza vaccines. Curr. Top. Microbiol. Immunol. 333, 43-82. doi: 10.1007/978-3-540-92165-3\_3

Fleming, D. M., Zambon, M., and Bartelds, A. I. (2000). Population estimates of persons presenting to general practitioners with influenza-like illness, 1987-96: a study of the demography of influenza-like illness in sentinel practice networks in England and Wales, and in the Netherlands. Epidemiol. Infect. 124, 245-253. doi: 10.1017/S0950268899003660

Ge, H., Wang, Y. F., Xu, J., Gu, Q., Liu, H. B., Xiao, P. G., et al. (2010). Anti-influenza agents from traditional Chinese medicine. Nat. Prod. Rep. 27, 1758-1780. doi: 10.1039/c0np00005a

Haruyama, T., and Nagata, K. (2013). Anti-influenza virus activity of Ginkgo biloba leaf extracts. J. Nat. Med. 67, 636-642. doi: 10.1007/s11418-012-0725-0

\section{ACKNOWLEDGMENTS}

We greatly appreciate Dr. Jong-Soo Lee, College of Veterinary Medicine, Chungnam National University and Korea Bank for Pathogenic Viruses for providing us the influenza A virus.

\section{SUPPLEMENTARY MATERIAL}

The Supplementary Material for this article can be found online at: http://journal.frontiersin.org/article/10.3389/fphar. 2016.00460/full\#supplementary-material

Hayden, F. G. (2006). Respiratory viral threats. Curr. Opin. Infect. Dis. 19, 169-178. doi: 10.1097/01.qco.0000216628.51563.b1

He, W., Han, H., Wang, W., and Gao, B. (2011). Anti-influenza virus effect of aqueous extracts from dandelion. Virol. J. 8, 538. doi: 10.1186/1743-422X8-538

Horvath, C. M. (2004). The Jak-STAT pathway stimulated by interferon alpha or interferon beta. Sci. STKE 2004:tr10.

Hurt, A. C., Holien, J. K., Parker, M., Kelso, A., and Barr, I. G. (2009). Zanamivirresistant influenza viruses with a novel neuraminidase mutation. J. Virol. 83, 10366-10373. doi: 10.1128/JVI.01200-09

Ison, M. G. (2011). Antivirals and resistance: influenza virus. Curr. Opin. Virol. 1, 563-573. doi: 10.1016/j.coviro.2011.09.002

Kaji, M., Fukuda, T., Tanaka, M., and Aizawa, H. (2005). A side effect of neuraminidase inhibitor in a patient with liver cirrhosis. J. Infect. Chemother. 11, 41-43. doi: 10.1007/s10156-004-0358-7

Khushboo, P. S., Jadhav, V. M., Kadam, V. J., and Sathe, N. S. (2010). Psoralea corylifolia Linn.-"Kushtanashini". Pharmacogn. Rev. 4, 69-76. doi: 10.4103/ 0973-7847.65331

Lazear, H. M., Lancaster, A., Wilkins, C., Suthar, M. S., Huang, A., Vick, S. C., et al. (2013). IRF-3, IRF-5, and IRF-7 coordinately regulate the type I IFN response in myeloid dendritic cells downstream of MAVS signaling. PLoS Pathog. 9:e1003118. doi: 10.1371/journal.ppat.100 3118

Makau, J. N., Watanabe, K., and Kobayashi, N. (2013). Anti-influenza activity of Alchemilla mollis extract: possible virucidal activity against influenza virus particles. Drug Discov. Ther. 7, 189-195.

Martin, K. W., and Ernst, E. (2003). Herbal medicines for treatment of bacterial infections: a review of controlled clinical trials. J. Antimicrob. Chemother. 51, 241-246. doi: 10.1093/jac/dkg087

Marié, I., Durbin, J. E., and Levy, D. E. (1998). Differential viral induction of distinct interferon-alpha genes by positive feedback through interferon regulatory factor-7. EMBO J. 17, 6660-6669. doi: 10.1093/emboj/17.22.6660

Meijer, A., Rebelo-De-Andrade, H., Correia, V., Besselaar, T., Drager-Dayal, R., Fry, A., et al. (2014). Global update on the susceptibility of human influenza viruses to neuraminidase inhibitors, 2012-2013. Antiviral Res. 110, 31-41. doi: 10.1016/j.antiviral.2014.07.001

Monto, A. S., and Sullivan, K. M. (1993). Acute respiratory illness in the community. Frequency of illness and the agents involved. Epidemiol. Infect. 110, 145-160. doi: 10.1017/S0950268800050779

Nakashima, K., Chanda, P. K., Deutsch, V., Banerjee, A. K., and Shatkin, A. J. (1979). Inactivation of influenza and vesicular stomatitis virion RNA polymerase activities by photoreaction with $4^{\prime}$-substituted psoralens. J. Virol. 32, 838-844.

Redfield, D. C., Richman, D. D., Oxman, M. N., and Kronenberg, L. H. (1981). Psoralen inactivation of influenza and herpes simplex viruses and of virusinfected cells. Infect. Immun. 32, 1216-1226.

Sato, M., Suemori, H., Hata, N., Asagiri, M., Ogasawara, K., Nakao, K., et al. (2000). Distinct and essential roles of transcription factors IRF-3 and IRF-7 in response to viruses for $I F N-\alpha / \beta$ gene induction. Immunity 13, 539-548. doi: 10.1016/S1074-7613(00)00053-4

Sharma, S., Tenoever, B. R., Grandvaux, N., Zhou, G. P., Lin, R., and Hiscott, J. (2003). Triggering the interferon antiviral response through 
an IKK-related pathway. Science 300, 1148-1151. doi: 10.1126/science.108 1315

Sheikh, F., Dickensheets, H., Gamero, A. M., Vogel, S. N., and Donnelly, R. P. (2014). An essential role for IFN-beta in the induction of IFN-stimulated gene expression by LPS in macrophages. J. Leukoc. Biol. 96, 591-600. doi: 10.1189/ jlb.2A0414-191R

Shoji, M., Arakaki, Y., Esumi, T., Kohnomi, S., Yamamoto, C., Suzuki, Y., et al. (2015). Bakuchiol Is a phenolic isoprenoid with novel enantiomer-selective anti-influenza A virus activity involving Nrf2 activation. J. Biol. Chem. 290, 28001-28017. doi: 10.1074/jbc.M115.669465

Talactac, M. R., Chowdhury, M. Y., Park, M. E., Weeratunga, P., Kim, T. H., Cho, W. K., et al. (2015). Antiviral effects of novel herbal medicine KIOM-C, on diverse viruses. PLoS ONE 10:e0125357. doi: 10.1371/journal.pone.0125357

Trinchieri, G. (2010). Type I interferon: friend or foe? J. Exp. Med. 207, 2053-2063. doi: 10.1084/jem.20101664

Yeh, J. Y., Coumar, M. S., Horng, J. T., Shiao, H. Y., Kuo, F. M., Lee, H. L., et al. (2010). Anti-influenza drug discovery: structure-activity relationship and mechanistic insight into novel angelicin derivatives. J. Med. Chem. 53, 1519-1533. doi: 10.1021/jm901570x
Zambon, M. C. (1999). Epidemiology and pathogenesis of influenza. J. Antimicrob. Chemother. 44 (Suppl. B), 3-9.

Zhang, X., Zhao, W., Wang, Y., Lu, J., and Chen, X. (2016). The chemical constituents and bioactivities of Psoralea corylifolia Linn: a review. Am. J. Chin. Med. 44, 35-60. doi: 10.1142/S0192415X16500038

Zhao, L., Huang, C., Shan, Z., Xiang, B., and Mei, L. (2005). Fingerprint analysis of Psoralea corylifolia L. by HPLC and LC-MS. J. Chromatogr. B Anal. Technol. Biomed. Life Sci. 821, 67-74. doi: 10.1016/j.jchromb.2005.04.008

Conflict of Interest Statement: The authors declare that the research was conducted in the absence of any commercial or financial relationships that could be construed as a potential conflict of interest.

Copyright (C) 2016 Choi, Jin, Kim, Oh, Yim, Cho and Ma. This is an open-access article distributed under the terms of the Creative Commons Attribution License (CC BY). The use, distribution or reproduction in other forums is permitted, provided the original author(s) or licensor are credited and that the original publication in this journal is cited, in accordance with accepted academic practice. No use, distribution or reproduction is permitted which does not comply with these terms. 